Article

\title{
Protective Mechanism of the Antioxidant Baicalein toward Hydroxyl Radical-Treated Bone Marrow-Derived Mesenchymal Stem Cells
}

\author{
Yage Tian ${ }^{1,2,+}$, Xican $\mathrm{Li}^{3,4, *,+} \mathbb{( \mathbb { D }}$, Hong Xie ${ }^{3,4}$, Xiaozhen Wang ${ }^{3}$, Yulu Xie ${ }^{3,4}$, Chuanbing Chen ${ }^{3}$ \\ and Dongfeng Chen $1,5, *$ (i) \\ 1 School of Basic Medical Science, Guangzhou University of Chinese Medicine, Guangzhou 510006, China; \\ rebecca-22222@163.com \\ 2 International Institute for Translational Chinese Medicine, Guangzhou University of Chinese Medicine, \\ Guangzhou 510006, China \\ 3 School of Chinese Herbal Medicine, Guangzhou University of Chinese Medicine, Guangzhou 510006, China; \\ xiehongxh1@163.com (H.X.); Jennywang2014@126.com (X.W.); xieyulu1900@163.com (Y.X.); \\ henchuanbing@gzucm.edu.cn (C.C.) \\ 4 Innovative Research \& Development Laboratory of TCM, Guangzhou University of Chinese Medicine, \\ Guangzhou 510006, China \\ 5 The Research Center of Basic Integrative Medicine, Guangzhou University of Chinese Medicine, \\ Guangzhou 510006, China \\ * Correspondence: lixican@126.com or lixc@gzucm.edu.cn (X.L.); cdf27212@21cn.com (D.C.); \\ Tel.: +86-20-3935-8076 (X.L.) \\ + These authors contributed equally to this work.
}

Received: 5 December 2017; Accepted: 17 January 2018; Published: 20 January 2018

\begin{abstract}
Our study explores the antioxidant and cytoprotective effects of baicalein and further discusses the possible mechanisms. A methyl thiazolyl tetrazolium (MTT) assay revealed that baicalein could considerably enhance the viability of hydroxyl radical-treated bone marrow-mesenchymal stem cells (bmMSCs) at 37-370 $\mu \mathrm{M}$. The highest viability rate was $120.4 \%$. In subsequent studies, baicalein was observed to effectively scavenge hydroxyl radical and PTIO $\bullet$ radicals, reducing $\mathrm{Fe}^{3+}$ and $\mathrm{Cu}^{2+}$ ions. In the $\mathrm{Fe}^{2+}$-chelating UV-vis spectra, mixing of baicalein with $\mathrm{Fe}^{2+}$ yielded two evident redshifts $(275 \rightarrow 279 \mathrm{~nm}$ and $324 \rightarrow 352 \mathrm{~nm})$ and a broad absorption peak $\left(\lambda_{\max } \approx 650 \mathrm{~nm}, \varepsilon=1.6 \times 10^{3} \mathrm{~L} \mathrm{~mol}^{-1} \cdot \mathrm{cm}^{-1}\right)$. Finally, we compared the $\mathrm{Fe}^{2+}$-chelating UV-vis spectra of baicalein and its analogues, including 5-hydroxyflavone, 6-hydroxyflavone, 7-hydroxyflavone, catechol, pyrogallol, and chrysin. This analysis revealed that the 4-keto group of the C-ring played a role. The 5,6,7-trihydroxy-group (pyrogallol group) in the A-ring served as an auxochrome, enhancing the absorbance of the UV-vis spectra and deepening the color of the $\mathrm{Fe}^{2+}$-complex. We concluded that baicalein, as an effective hydroxyl radical-scavenger, can protect bmMSCs from hydroxyl radical-mediated oxidative stress. Its hydroxyl radical-scavenging effects are likely exerted via two pathways: direct scavenging of hydroxyl radicals, possibly through electron transfer, and indirect inhibition of hydroxyl radical generation via $\mathrm{Fe}^{2+}$ chelation through the 4-keto-5,6,7-trihydroxy groups.
\end{abstract}

Keywords: baicalein; 5,6,7-trihydroxyflavone; e-transfer; bmMSCs; $\mathrm{Fe}^{2+}$-chelating; antioxidant mechanism

\section{Introduction}

Hydrogen peroxide $\left(\mathrm{H}_{2} \mathrm{O}_{2}\right)$ can cross cell membranes freely and are often found in biological systems [1]. When mixed with ferrous iron $\left(\mathrm{Fe}^{2+}\right)$, it will undergo the Fenton reaction $\left(\mathrm{Fe}^{2+}+\mathrm{H}_{2} \mathrm{O}_{2} \rightarrow\right.$ $\left.\mathrm{Fe}^{3+}+\bullet \mathrm{OH}+\mathrm{HO}^{-}\right)$, generating a hydroxyl radical $(\bullet \mathrm{OH})$, well-known as the most harmful reactive 
oxygen species (ROS). Hydroxyl radicals can attack all types of cellular biomolecules (especially DNA) to cause oxidative stress [2,3].

Oxidative stress not only lowers viability of bone marrow-derived mesenchymal stem cells (bmMSCs), but also induces their differentiation [3,4]. It is reported that mild oxidative stress can induce differentiation of bmMSCs to adipose cells, but not to osteose or nerve cells $[5,6]$. Thus, iron overload, a cause of $\bullet \mathrm{OH}$ radical generation, can usually lead to bone loss [7]. These aforementioned detrimental effects of oxidative stress currently limit the clinical application of bmMSC transplantation for neurodegenerative diseases (e.g., Parkinson's disease) [8] and bone diseases (e.g., osteoporosis) [9,10]. As such, scientists are searching for an effective antioxidant from natural products [11] or synthetic compounds $[12,13]$ to relieve $\bullet \mathrm{OH}$ radical-mediated oxidative stress, to improve bmMSCs viability enough for the clinical application [14].

Baicalein (Figure 1), a natural flavonoid occurring in traditional Chinese herbal medicine, Scutellaria baicalensis Georgi, is predicted to be useful as an antioxidant. Recently, baicalein has been demonstrated to suppress the early stages of adipogenesis [15,16] and regulate bone formation [17]. In addition, baicalein has been reported to protect HS-SY5Y cells from hydrogen peroxide-induced oxidative stress [18] and to attenuate neurological injury in rats [19].
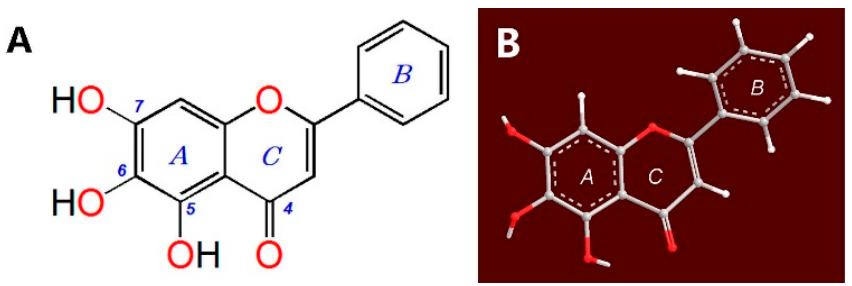

Figure 1. Structure (A) and preferential conformation-based ball-and-stick model (B) of baicalein (5,6,7-trihydroxyflavone).

Nevertheless, there is no direct evidence for the beneficial effects of baicalein toward $\bullet \mathrm{OH}$-treated bmMSCs. This study therefore used a methyl thiazolyl tetrazolium (MTT) assay to assess its protective effects towards $\bullet \mathrm{OH}$-treated bmMSCs, thus providing information for the use of baicalein in bmMSC transplantation technology.

More importantly, there are some disputes regarding the antioxidation mechanisms (especially $\mathrm{Fe}^{2+}$-chelation) of baicalein. Yoshino and colleagues have suggested that baicalein could inhibit $\bullet \mathrm{OH}$ radical generation [20], while Shieh and colleagues have reported that baicalein could not scavenge $\bullet \mathrm{OH}$ [21]. Regarding $\mathrm{Fe}^{2+}$-chelation chemistry, Ren and colleagues stated that the 4-keto group of flavonoids plays a critical role in this process [22], while Perez and colleagues argued that $\mathrm{Fe}^{2+}$-chelation mainly occurred at the 6,7-dihydroxyl groups in flavonoids [23]. Thus, our study used various chemical approaches to explore the possible antioxidation mechanisms, especially the $\mathrm{Fe}^{2+}$-chelation pathway. We believe that this study will help settle the above disputes.

\section{Results and Discussion}

As seen in Figure 2, in the model group, bmMSCs damaged by $\bullet \mathrm{OH}$ radicals showed only $52.9 \pm 12.0 \%$ viability. However, when damaged bmMSCs were further treated with baicalein at $10-100 \mu \mathrm{g} / \mathrm{mL}(37-370 \mu \mathrm{M})$, the viability was completely restored, and further increased to $120.7 \pm 4.3 \%$ (baicalein group). This result suggests that baicalein protects $\bullet \mathrm{OH}$ radical-treated bmMSCs, as supported by previous studies [24,25]. 


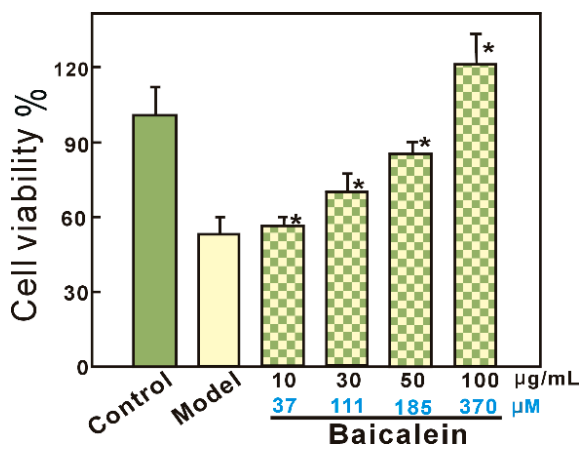

Figure 2. Protective effect of baicalein toward $\bullet \mathrm{OH}$-treated bmMSCs. Cell viability was assessed using the MTT method. $\bullet \mathrm{OH}$ radicals were generated by addition of $\mathrm{FeCl}_{2}(100 \mu \mathrm{M})$ followed by $\mathrm{H}_{2} \mathrm{O}_{2}$ $(50 \mu \mathrm{M})$. The control group was cultured in medium only, while the model group was treated with $\bullet \mathrm{OH}$ radicals. The baicalein group was treated by $\bullet \mathrm{OH}$ followed by baicalein. Each value is expressed as the mean $\pm \mathrm{SD}, n=3$; * Significant difference vs. model group, $p<0.05$. bmMSCs, bone marrow-derived mesenchymal stem cells; MTT, methyl thiazolyl tetrazolium.

The damage to the cells may be largely due to $\bullet \mathrm{OH}$ attack, as $\bullet \mathrm{OH}$ radicals are much more toxic than $\mathrm{H}_{2} \mathrm{O}_{2}$ alone. Correspondingly, the above cytoprotective effects of baicalein are attributable to its $\bullet \mathrm{OH}$-scavenging ability $[26,27]$. In fact, in the $\bullet \mathrm{OH}$-scavenging assay based on deoxyribose degradation, baicalein was observed to have an effective dose-dependent response (Figure 3A).

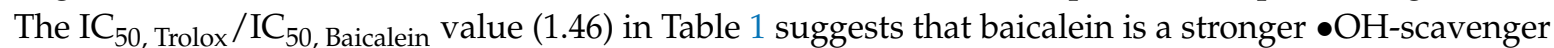
than the standard antioxidant, Trolox. Our data appear to support the opinions of Yoshino [20], and disagree with those of Shieh [21].
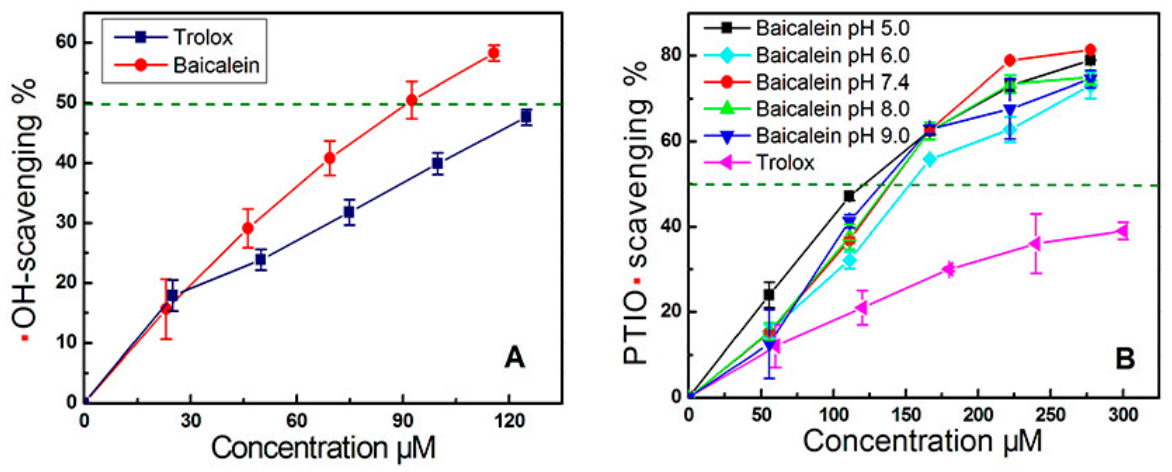

Figure 3. Dose-response curves of baicalein in the $\bullet \mathrm{OH}$-scavenging assay $(\mathbf{A})$ and in PTIO•-scavenging assay (B). PTIO•-scavenging assay was conducted at $\mathrm{pH}$ 5.0, 6.0, 7.4, 8.0, and 9.0. Trolox served as positive control. Each value is expressed as the mean $\pm \mathrm{SD}, n=3$.

Table 1. $\mathrm{IC}_{50}$ values of baicalein and Trolox in various assays.

\begin{tabular}{cccc}
\hline Assays & $\begin{array}{c}\text { Baicalein } \\
\boldsymbol{\mu M}\end{array}$ & $\begin{array}{c}\text { Trolox } \\
\boldsymbol{\mu M}\end{array}$ & $\begin{array}{c}\text { Ratio value }^{\mathbf{M}} \\
\mathbf{I C}_{\mathbf{5 0}, \text { Trolox }} / \mathbf{I C}_{\mathbf{5 0} \text {, Baicalein }}\end{array}$ \\
\hline$\bullet$ OH-scavenging & $93.7 \pm 1.6^{\mathrm{a}}$ & $137.6 \pm 3.6^{\mathrm{b}}$ & 1.46 \\
PTIO• scavenging & $188.7 \pm 13.1^{\mathrm{a}}$ & $384.2 \pm 23.3^{\mathrm{b}}$ & 2.03 \\
$\mathrm{Cu}^{2+}$ reducing & $19.0 \pm 0.1^{\mathrm{a}}$ & $44.6 \pm 1.5^{\mathrm{b}}$ & 2.34 \\
FRAP & $11.1 \pm 0.0^{\mathrm{a}}$ & $12.0 \pm 0.0^{\mathrm{a}}$ & 0.96 \\
\hline
\end{tabular}

$\mathrm{IC}_{50}$ value was defined as the final concentration of $50 \%$ radical-scavenging (relative reducing power), was calculated by linear regression analysis, and is expressed as the mean $\pm \mathrm{SD}(n=3)$. Linear regression was analyzed using Origin 6.0 professional software. The mean values with different superscripts ( $\mathrm{a}$ or $\mathrm{b}$ ) in the same row, are significantly different $(p<0.05) .{ }^{*}$ The assay was conducted at $\mathrm{pH} 7.4$. The ratio value is defined as $\mathrm{IC}_{50,}, \mathrm{Trol}_{0 x} / \mathrm{IC}_{50, \text { Baicalein }}$. FRAP, $\mathrm{Fe}^{3+}$ reducing antioxidant power assay. PTIO•, 2-phenyl-4,4,5,5-tetramethylimidazoline-1-oxyl-3-oxide radical. 
Since $\bullet \mathrm{OH}$ generation relies on $\mathrm{Fe}^{2+}$ catalysis of the Fenton reaction, attenuating $\mathrm{Fe}^{2+}$ levels via a chelation pathway can indirectly inhibit the production of $\bullet \mathrm{OH}$ radicals in cells [28]. This is sometimes called indirect $\bullet \mathrm{OH}$-inhibition. Correspondingly, direct scavenging of $\bullet \mathrm{OH}$-radicals that were already generated is known as direct $\bullet \mathrm{OH}$-scavenging [29]. However, it is impossible to verify whether $\bullet \mathrm{OH}$ radicals are directly scavenged, due to the transience of the $\bullet \mathrm{OH}$ radical (half-life of $10^{-9} \mathrm{~s}$ ). We therefore used a stable oxygen-centered PTIO• radical for the exploration. As seen in Figure 3B, baicalein scavenged PTIO• radicals in a dose-dependent manner at various $\mathrm{pH}$ values. These data suggest that baicalein may scavenge $\bullet \mathrm{OH}$ directly.

The evidence from cyclic voltammetry suggested that at a $\mathrm{pH} \leq 5.0$, PTIO• could be scavenged via an electron transfer (ET) pathway [30]. At $\mathrm{pH}$ 5.0, baicalein could scavenge PTIO• in a concentration-dependent manner (Figure 3B), suggesting that baicalein exerts its effect possibly via ET. This was further supported by our $\mathrm{Cu}^{2+}$-reducing and $\mathrm{Fe}^{3+}$-reducing (FRAP) assays. As illustrated in Figure 4, baicalein, in addition to the positive control Trolox, increased the relative $\mathrm{Cu}^{2+}$-reducing and $\mathrm{Fe}^{3+}$-reducing percentages, in a concentration-dependent manner. In particular, the FRAP assay demonstrated the presence of an ET reaction, because in acidic solution (below $\mathrm{pH}$ 3.6), a high concentration of $\mathrm{H}^{+}$successfully suppresses $\mathrm{H}^{+}$ionization from a phenolic antioxidant (i.e., baicalein) [31]. The above $\mathrm{Fe}^{3+}$-reducing reaction of baicalein, can therefore be viewed as merely an ET process. Recently, Marino and colleagues used density functional theory to predict that during the process of $\bullet \mathrm{OH}$-scavenging of gallic acid (a phenolic antioxidant), an ET reaction was involved [32]. All of this experimental and theoretical evidence suggests that an ET reaction may involve the direct -OH-scavenging process of baicalein.
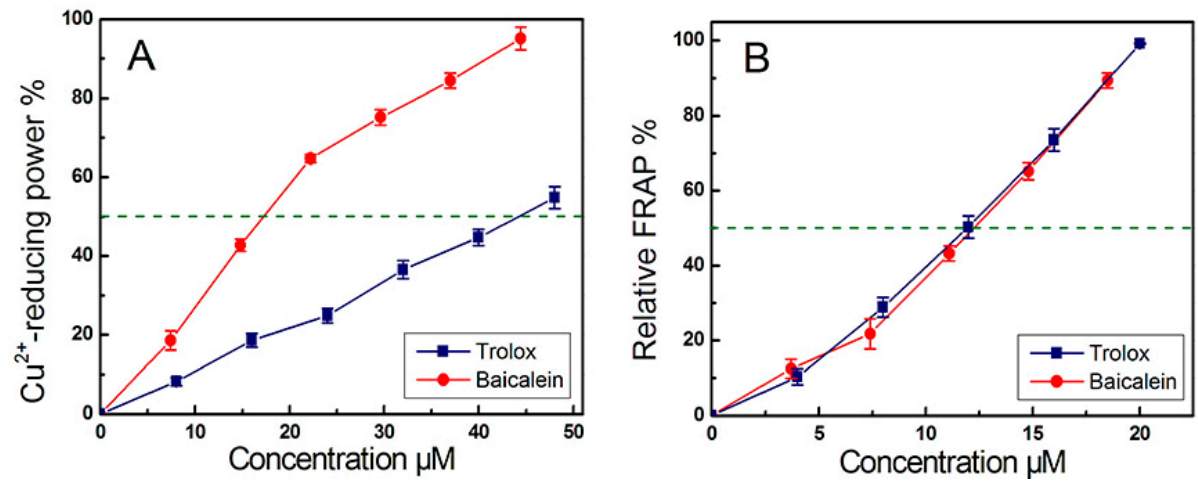

Figure 4. Dose-response curves of baicalein in $\mathrm{Cu}^{2+}$-reducing (A) and $\mathrm{Fe}^{3+}$-reducing (FRAP, B) assays (Values are expressed as the mean $\pm \mathrm{SD}, n=3$ ).

As mentioned in our previous report [33], $\mathrm{Fe}^{3+}$-reduction by an antioxidant may form a new recycle for supplying $\mathrm{Fe}^{2+}$ ions. This is regarded as being a cause of pro-oxidation [34]. In fact, as a flavonoid, baicalein has been reported to possess pro-oxidation potential, by Huang and colleagues [35]. Yoshino and Murakami have argued that baicalein could enhance the oxidation of $\mathrm{Fe}^{2+}$ to block this pro-oxidation mechanism [20]. These contradictory findings may be due to the differences in flavonoid concentrations [36]. Nevertheless, in the present study, no pro-oxidation potential was observed in cellular assays (Figure 2), or in antioxidant assays in vitro (Figure 3A).

In addition to direct $\bullet \mathrm{OH}$-scavenging, an indirect $\bullet \mathrm{OH}$-inhibition pathway (i.e., $\mathrm{Fe}^{2+}$-chelation) was also investigated in our study. As seen in Figure 5A,B, after mixing with $\mathrm{Fe}^{2+}$ solutions, baicalein presented stronger UV peaks and a darker green color, suggesting that $\mathrm{Fe}^{2+}$-chelation may occur and that baicalein may indirectly inhibit $\bullet \mathrm{OH}$ radical production via an $\mathrm{Fe}^{2+}$-chelation pathway. However, there is a dispute regarding the $\mathrm{Fe}^{2+}$-chelating site and the role of the 4-keto group, as mentioned above. To address this problem, we selected six analogues for comparative study; 5-hydroxyflavone, 6-hydroxyflavone, 7-hydroxyflavone, catechol, pyrogallol, and chrysin. 

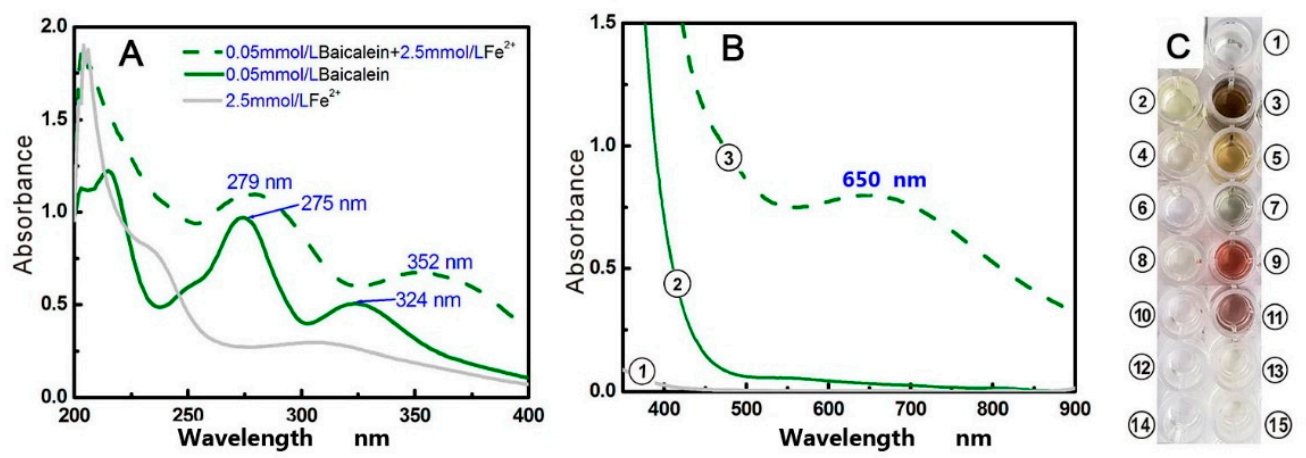

Figure 5. (A) UV spectra of a low-concentration of baicalein and a baicalein-Fe ${ }^{2+}$ complex; (B) vis spectra of high-concentration baicalein and the baicalein- $\mathrm{Fe}^{2+}$ complex; (C) colors of the various solutions. (1) $25 \mathrm{mM} \mathrm{Fe}^{2+}$; (2) $0.5 \mathrm{mM}$ baicalein; (3) $0.5 \mathrm{mM}$ baicalein $+25 \mathrm{mM} \mathrm{Fe}^{2+}$; (4) $0.5 \mathrm{mM}$ pyrogallol; (5) $0.5 \mathrm{mM}$ pyrogallol + $25 \mathrm{mM} \mathrm{Fe}^{2+}$; (6) $0.5 \mathrm{mM}$ catechol; (7) $0.5 \mathrm{mM}$ catechol + $25 \mathrm{mM}$ $\mathrm{Fe}^{2+}$; (8) $0.5 \mathrm{mM}$ chrysin; (9) $0.5 \mathrm{mM}$ chrysin + $25 \mathrm{mM} \mathrm{Fe}{ }^{2+}$; (10) $0.5 \mathrm{mM}$ 5-hydroxyflavone; (11) $0.5 \mathrm{mM}$ 5-hydroxyflavone $+25 \mathrm{mM} \mathrm{Fe}^{2+}$; (12) $0.5 \mathrm{mM}$ 6-hydroxyflavone; (13) $0.5 \mathrm{mM}$ 6-hydroxyflavone $+25 \mathrm{mM}$ $\mathrm{Fe}^{2+}$; (14) $0.5 \mathrm{mM} 7$-hydroxyflavone; and (15) $0.5 \mathrm{mM} 7$-hydroxyflavone $+25 \mathrm{mM} \mathrm{Fe}^{2+}$. The UV spectra of a low concentration of chrysin, 5-hydroxyflavone, pyrogallol, and chrysin- $\mathrm{Fe}^{2+}$ complex are detailed in Supplementary 2. The vis spectra of (4)_(15) are detailed in Supplementary 1).

As seen in Supplementary 1 and Figure 5, when mixed with $\mathrm{Fe}^{2+}$, neither the 6-hydroxyflavone solution nor the 7-hydroxyflavone solution developed color, and gave corresponding peaks in the visible spectra. Our results agree with previously published literature reporting that the isolated hydroxyl-groups cannot chelate $\mathrm{Fe}^{2+}$ [37]. In comparison, when a hydroxyl-group is adjacent to another hydroxyl-group, the situation may be different. As seen in Figure 5 and Supplementary 1, ortho-dihydroxy groups (i.e., catechol groups) or adjacent 1,2,3-trihydroxy-groups (i.e., pyrogallol group), can chelate $\mathrm{Fe}^{2+}$ to produce a light color and weaker visible spectra. This indicates that $\mathrm{Fe}^{2+}$-chelation requires at least two adjacent dihydroxy groups. This is consistent with previous reports that flavones with catechol group have a similar $\mathrm{Fe}^{2+}$-chelating capacity to those with pyrogallol group $[27,37,38]$.

When a hydroxyl-group is adjacent to a keto group, it can possess $\mathrm{Fe}^{2+}$-chelating potential. As seen in Supplementary 1 and Figure 5, 5-hydroxyflavone could also chelate $\mathrm{Fe}^{2+}$ to yield a dark color and an evident visible spectra peak $\left(\lambda_{\max }=557 \mathrm{~nm}, \varepsilon=1.4 \times 10^{3} \mathrm{~L} \mathrm{~mol}^{-1} \cdot \mathrm{cm}^{-1}\right)$. This result clearly suggests that adjacent hydroxyl-keto groups (i.e., 4-keto-5-hydroxyl) can chelate $\mathrm{Fe}^{2+}$. Chrysin, with a 4-keto-5-hydroxyl group, could also chelate $\mathrm{Fe}^{2+}$ to produce a darker orange color and stronger UV-vis spectra $\left(\lambda_{\max }=528 \mathrm{~nm}, \varepsilon=1.5 \times 10^{3} \mathrm{~L} \mathrm{~mol}^{-1} \cdot \mathrm{cm}^{-1}\right)$. We therefore conclude that adjacent hydroxyl-keto groups possess $\mathrm{Fe}^{2+}$-chelating potential. This phenomenon is similar to the copper chelation of flavonol, which is reported to have the two most efficient copper chelation sites (i.e., the 3-hydroxy-4-keto group and the 5,6,7-trihydroxy-group) [39].

Importantly, the spectra of hydroxyl-groups differ from those of keto groups. A keto group attached to an aromatic nucleus can act as a chromophore, while a phenolic hydroxyl-group can act only as an auxochrome group. Therefore, adjacent hydroxyl-keto groups can generate darker colors and stronger visible spectra peaks than those produced by catechol groups or pyrogallol groups. It is clear that if a 4-keto group is adjacent to a hydroxyl-group in flavonoids, the 4-keto group actually plays a critical role in $\mathrm{Fe}^{2+}$-chelation reactions. Our data undoubtedly support the findings of Ren [22] and several other researchers [40,41] and are contradictory to the opinions of Perez [23].

Based on the above discussion, we deduce that baicalein actually possesses three $\mathrm{Fe}^{2+}$-chelating sites; between the 5,6-dihydroxyl groups, between the 6,7-dihydroxyl groups, and between the 4-keto-5-hydroxy groups. The preferential conformation-based ball-and-stick model indicates that the huge 4-keto-5,6,7-trihydroxy groups have a planar configuration (Figure 1B and Supplementary 3), 
and thus, the $\mathrm{Fe}^{2+}$-chelating complex is stable. The proposed $\mathrm{Fe}^{2+}$-chelation reaction of baicalein is shown in Figure $6[27,37]$.

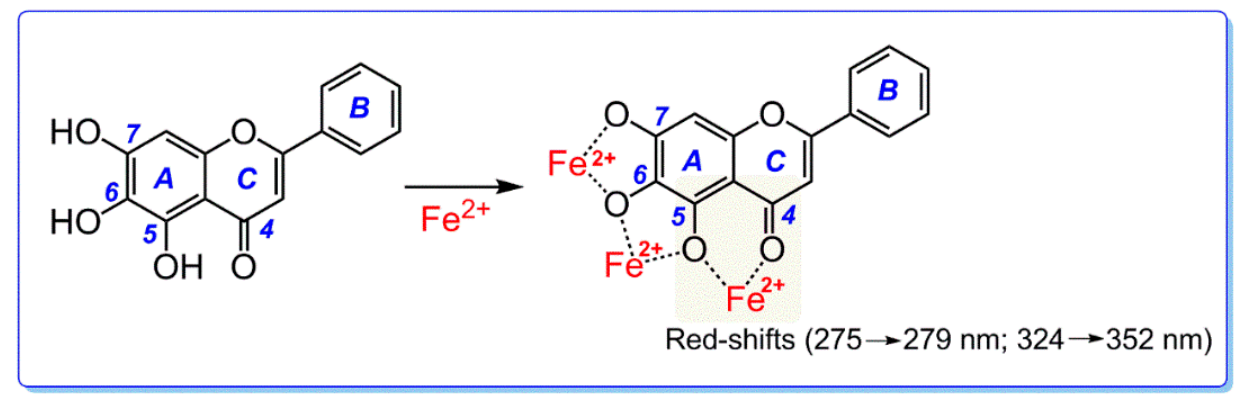

Figure 6. The proposed $\mathrm{Fe}^{2+}$-chelation reaction of baicalein (including UV-vis spectra assignments).

As seen in Figure 5A, baicalein generated two red shifts $(275 \mathrm{~nm} \rightarrow 279 \mathrm{~nm}$ and $324 \mathrm{~nm} \rightarrow 352 \mathrm{~nm}$ ) in the UV spectra bands. The fact that neither catechol nor pyrogallol without 4-keto exhibited similar peaks, while chrysin with 4-keto gave similar peaks, implies that the two redshifts can thus be attributed to the $\mathrm{Fe}^{2+}$-chelation reaction at the 4-keto-5-hydroxy group (Supplementary 2).

In the visible spectra, baicalein produced a broader, stronger peak (approximately $650 \mathrm{~nm}$ ) than any other analogue (Figure $5 \mathrm{~B}$ ). The broad, strong peak is also partly from $\mathrm{Fe}^{2+}$-chelation at the 4-keto-5-hydroxy group. From the perspective of spectroscopy, the three phenolic hydroxyl-groups at the 5, 6, and 7-positions, as auxochrome groups, can enhance absorbance of UV-vis spectra peak. In other words, the broad, strong peak near $650 \mathrm{~nm}$ can be regarded as the overlying of UV-vis spectra from the above three $\mathrm{Fe}^{2+}$-chelating sites. Correspondingly, baicalein also generated the darkest color in the $\mathrm{Fe}^{2+}$-chelation reaction, compared to the six analogues.

It must be noted that (1) despite many reports on the metal-chelating ability of flavonoids [37-42] and descriptions of $\mathrm{Na}^{+}\left(\mathrm{Al}^{3+}\right)$ interacting with flavonoids [43], no study has clearly indicated the roles of specific groups within flavonoids; (2) The 4-keto group has been disregarded because the flavonoid levels exceeded the $\mathrm{Fe}^{2+}$ level in the previous experiment. In this case, two baicalein molecules are able to jointly chelate one $\mathrm{Fe}^{2+}$ ion (Figure 7) [23]. However, even with the intake of sufficient flavanone-enriched juices or foods, flavonoids levels $(1.75 \pm 0.35 \mu \mathrm{M}$ [44], $2.16 \mu \mathrm{M}$, and $3.47 \mu \mathrm{M}$ [45]) are still much lower than $\mathrm{Fe}^{2+}$ levels (34.95 $\pm 13.35 \mu \mathrm{M}$ [46]) in human plasma. Thus, the experimental result that 4-keto plays a negligible role in $\mathrm{Fe}^{2+}$-chelation of flavonoids [23] lacks biological relevance.<smiles>O=c1cc(-c2ccccc2)oc2c(O)c3c(cc12)O[C@H]([C+]=COc1cc2oc(-c4ccccc4)cc(=O)c2c(O)c1O)O3</smiles>

Figure 7. The structure allowing baicalein molecules to jointly chelate one $\mathrm{Fe}^{2+}$ ion [23].

Taken together, when baicalein chelates $\mathrm{Fe}^{2+}$ ions in a biological system, the 4-keto group of the C-ring actually plays a key role, similar to a chromophore. Of course, the 4-keto must be adjacent a hydroxy-group (i.e., the site between 4 -keto and 5-hydroxy groups). $\mathrm{Fe}^{2+}$-chelation can also occur in the 5,6,7-trihydroxy-groups (i.e., the site between the 5,6-dihydroxyl groups and the site between 6,7-dihydroxyl groups). However, such $\mathrm{Fe}^{2+}$-chelation at the 5,6,7-trihydroxy-group plays a minor role, similar to an auxochrome; it can enhance the $\mathrm{Fe}^{2+}$-chelating UV-vis spectra absorbance and $\mathrm{Fe}^{2+}$-complex color. Thus, the $\mathrm{Fe}^{2+}$-chelation reaction of baicalein occurs in 4-keto-5,6,7-trihydroxy groups, among which 4-keto groups play a key role. 


\section{Materials and Methods}

\subsection{Chemicals and Animals}

Baicalein (CAS number: 491-67-8, 98\%) and chrysin (CAS number: 480-40-0, 98\%) were obtained from Chengdu Biopurify Phytochemicals, Ltd. (Chengdu, China, Supplementary 4); 5-Hydroxylflavone (CAS number: 491-78-1, 98\%), 6-hydroxylflavone (CAS number: 6665-83-4, 98\%), 7-hydroxylflavone (CAS number: 6665-86-7, 98\%), and 2-phenyl-4,4,5,5-tetramethylimidazoline-1-oxyl-3-oxide radical (PTIO•) were from TCI Development Co., Ltd. (Shanghai, China); ( \pm )-6-Hydroxyl-2,5,7,8-tetramethlychromane-2-carboxylic acid (Trolox), 2,9-dimethyl-1,10-phenanthroline (neocuproine), 2,4,6-tripyridyltriazine (TPTZ), catechol, pyrogallol, and 3-(4,5-dimethylthiazol-2-yl)-2,5-diphenyltetrazolium bromide (MTT) were from Sigma-Aldrich Shanghai Trading Co. (Shanghai, China). Deoxyribose was obtained from Amresco, Inc. (Solon, OH, USA). Dulbecco's modified Eagle's medium (DMEM) and fetal bovine serum (FBS) were purchased from Gibco (Grand Island, NY, USA); CD44 and Proteinase K were purchased from Wuhan Boster Co., Ltd. (Wuhan, China). All other reagents were of analytical grade. Sprague-Dawley (SD) rats 4 weeks of age were obtained from the animal center of the Guangzhou University of Chinese Medicine. The protocol of this experiment was performed under the supervision of the Institutional Animal Ethics Committee at the Guangzhou University of Chinese Medicine.

\subsection{Protective Effect against $\bullet \mathrm{OH}$-Induced Damage to bmMSCs (MTT Assay)}

The bmMSCs were prepared by our laboratory from four-week-old SD rats. The experimental procedures were based on our previous study [47] and are shown in Figure 8A. The resulting bmMSCs were evaluated for the purity by flow cytometry. Only bmMSCs with 95-97\% purity could be further used for the MTT assay to evaluate the cytoprotective effect of baicalein (Figure 8B) [3,27].

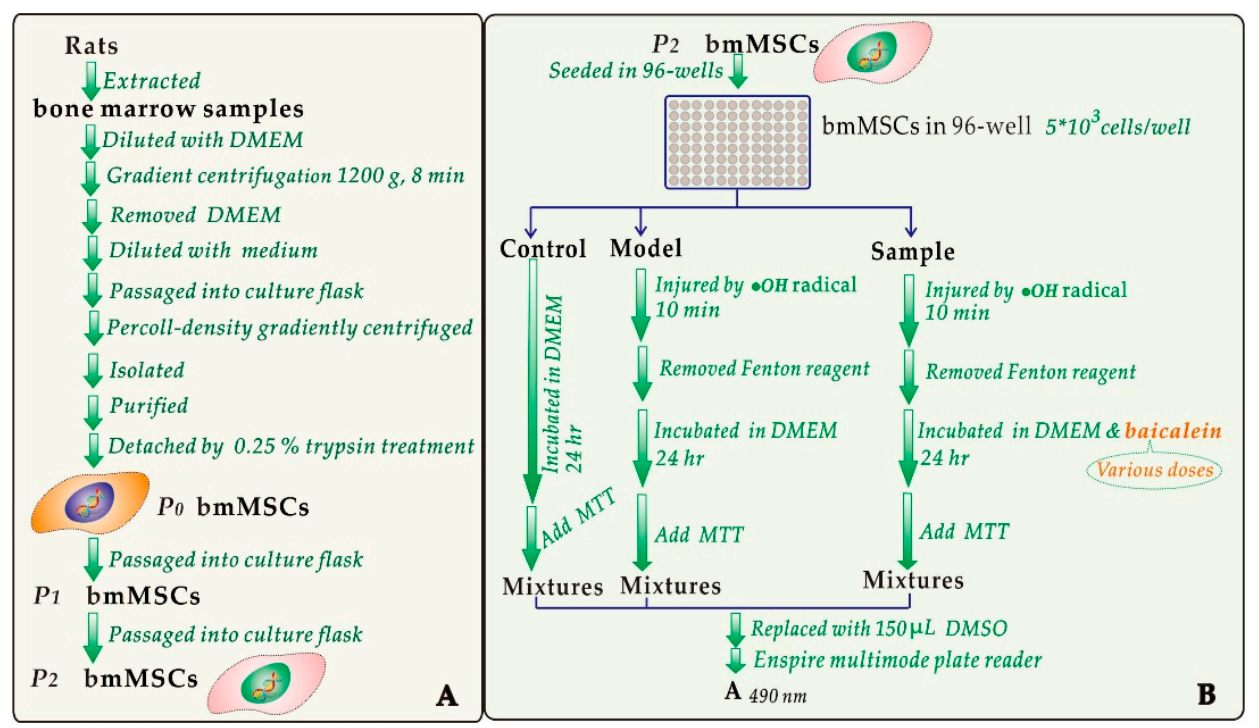

Figure 8. Experimental procedures for the preparation and culture of bmMSCs (A) and for the MTT assay (B).

(Enspire multimode plate reader was the product of Perkin Elmer Singapore Pte. Ltd., Singapore). Each test was repeated in five independent wells. MTT was used at $5 \mathrm{mg} / \mathrm{mL}$ (in PBS), and the addition volume was $20 \mu \mathrm{L}$. The addition of Fenton reagent was conducted by injection of $\mathrm{FeCl}_{2}(100 \mu \mathrm{M})$ followed by $\mathrm{H}_{2} \mathrm{O}_{2}(50 \mu \mathrm{M})$. 


\subsection{Hydroxyl Radical $(\bullet \mathrm{OH})$ Scavenging Assay}

The $\bullet \mathrm{OH}$-scavenging activity was investigated using our method [48]. In brief, all test samples were dissolved in ethanol $(1 \mathrm{mg} / \mathrm{mL})$, and a $10-50 \mu \mathrm{L}$ sample solution was transferred to mini tubes; the ethanol solvent was then removed at $80{ }^{\circ} \mathrm{C}$ to eliminate its interference. The reactions were performed in $0.2 \mathrm{M}$ phosphate buffer ( $\mathrm{pH}$ 7.4) containing $2.8 \mathrm{mM}$ deoxyribose, $2.8 \mathrm{mM} \mathrm{H}_{2} \mathrm{O}_{2}, 25 \mu \mathrm{M}$ $\mathrm{FeCl}_{3} 80 \mu \mathrm{M} \mathrm{Na}{ }_{2} \mathrm{EDTA}$, and the test sample (10-50 $\left.\mu \mathrm{g}\right)$. The reaction was started by adding ascorbic acid to a final concentration of $100 \mu \mathrm{M}$, and the reaction mixture (600 $\mu \mathrm{L}$ in total) was incubated for $20 \mathrm{~min}$ at $50{ }^{\circ} \mathrm{C}$ in a water bath. After incubation, the color was developed by adding $0.5 \mathrm{~mL}$ of 2-thiobarbituric acid $(1 \mathrm{~g} / 100 \mathrm{~mL})$ followed by $0.5 \mathrm{~mL}$ of trichloroacetic acid $(5 \mathrm{~g} / 100 \mathrm{~mL})$ and heating the sample in a boiling water bath for $15 \mathrm{~min}$. The sample was cooled and diluted twofold with $95 \%$ ethanol, and the absorbance was measured at $532 \mathrm{~nm}$ against buffer (as blank). The reaction mixture not containing test sample was used as a control. The scavenging activity on hydroxyl radicals was expressed as

$$
\text { Inhibition } \%=\frac{A_{0}-A}{A_{0}} \times 100 \%
$$

where $A_{0}$ is the absorbance of the control without sample and $A$ is the absorbance of the reaction mixture with sample.

\subsection{PTIO• Scavenging Assay}

The PTIO• scavenging assay was also based on our method [49]. In the PTIO• scavenging assay, $80 \mu \mathrm{L}$ of an aqueous PTIO• solution $(0.1 \mathrm{mM})$ was mixed with $20 \mu \mathrm{L}$ of phosphate buffer (pH 5.0, 6.0, 7.4, 8.0, and 9.0) with the sample at various concentrations. The mixture was maintained at $37^{\circ} \mathrm{C}$ for $30 \mathrm{~min}$, and the absorbance at $560 \mathrm{~nm}$ was measured using a microplate reader (Multiskan FC, Thermo Scientific, Shanghai, China). The PTIO• inhibition percentage was calculated using the formula described in Section 3.3.

\section{5. $\mathrm{C} u^{2+}$-Reducing Power Assay}

The cupric ion $\left(\mathrm{Cu}^{2+}\right)$ reducing power capacity was based on a published method [50] with slight modification. Briefly, $250 \mu \mathrm{L}$ of a $\mathrm{CuSO}_{4}$ aqueous solution $(10 \mathrm{mM}), 250 \mu \mathrm{L}$ of a neocuproine ethanolic solution $(7.5 \mathrm{mM})$ and $250 \mu \mathrm{L}$ of a $\mathrm{CH}_{3} \mathrm{COONH}_{4}$ buffer solution $(100 \mathrm{mM}, \mathrm{pH} 7.0)$ were added to a test tube containing baicalein $(2-12 \mu \mathrm{L})$. The total volume was adjusted with the buffer to $1 \mathrm{~mL}$, and the solution was mixed vigorously. The absorbance compared to a buffer blank was measured at $450 \mathrm{~nm}$ after $30 \mathrm{~min}$. Increased absorbance of neocuproine- $\mathrm{Cu}^{+}$complex in the reaction mixture indicates increased reduction capability. Trolox was used as a positive control. The percentage reducing power of the sample compared to the maximum absorbance tested in baicalein at $12 \mu \mathrm{g} / \mathrm{mL}$ was calculated based on the following formula:

$$
\text { Relative reducing effect } \%=\frac{A-A_{\min }}{A_{\max }-A_{\min }} \times 100 \%
$$

where $A_{\min }$ is the absorbance of the control without sample, $A$ is the absorbance of the reaction mixture with sample, and $A_{\max }$ is the greatest absorbance of the reaction mixture with sample.

\subsection{Ferric $\left(\mathrm{Fe}^{3+}\right)$ Reducing Antioxidant Power (FRAP) Assay}

The FRAP assay was adapted from Benzie and Strain [51]. Briefly, the FRAP reagent was freshly prepared by mixing $10 \mathrm{mM}$ TPTZ, $20 \mathrm{mM} \mathrm{FeCl}_{3}$ and $0.25 \mathrm{M} \mathrm{pH} 3.6$ acetate buffer at 1:1:10 (volume ratio). The test sample $(x=1-5 \mu \mathrm{L}, 0.1 \mathrm{mg} / \mathrm{mL})$ was added to $(20-x) \mu \mathrm{L}$ of $95 \%$ ethanol followed by $80 \mu \mathrm{L}$ of FRAP reagent. The absorbance was measured at $595 \mathrm{~nm}$ after a 30-min incubation at ambient temperatures using distilled water as the blank. The relative reducing power of the sample compared to the maximum absorbance was calculated by the formula presented in Section 3.5. 


\subsection{Ultraviolet-Visible (UV-Vis) Spectra Determination of $\mathrm{Fe}^{2+}$ Binding}

UV-vis spectral determination was conducted according to the published method [52,53] with minor modifications. In brief, $260 \mu \mathrm{L}$ of a methanolic solution of baicalein $(1 \mathrm{mg} / \mathrm{mL})$ and $400 \mu \mathrm{L}$ of an aqueous solution of $\mathrm{FeCl}_{2} \cdot 4 \mathrm{H}_{2} \mathrm{O}(25 \mathrm{mg} / \mathrm{mL})$ were added to $1340 \mu \mathrm{L}$ of methanol. The solution was mixed vigorously and incubated at room temperature for $30 \mathrm{~min}$. Subsequently, the product mixture was collected, and a spectrum was obtained from 200 to $900 \mathrm{~nm}$ using a UV-Vis spectrophotometer (Unico 2600A, Shanghai, China). Next, $200 \mu \mathrm{L}$ of the supernatant was transferred to a 96-well plate and imaged using a smartphone (Huawei, Honor 8, Shenzhen, China).

\subsection{Statistical Analysis}

Each experiment was performed in triplicate, and the data were recorded as the mean \pm SD (standard deviation). The $\mathrm{IC}_{50}$ value was defined as the final concentration causing $50 \%$ radical inhibition (or relative reducing power). Statistical comparisons were made by one-way ANOVA to detect significant differences using SPSS 13.0 (SPSS Inc., Chicago, IL, USA) for Windows. $p<0.05$ was considered to be statistically significant.

\section{Conclusions}

Baicalein, as an effective hydroxyl radical-scavenger, can protect bmMSCs from hydroxyl radical-induced oxidative stress. Baicalein scavenges hydroxyl radicals through two pathways: direct scavenging of hydroxyl radicals via an ET pathway, and indirect inhibition of hydroxyl radical production via an $\mathrm{Fe}^{2+}$-chelation pathway, which occurs in 4-keto-5,6,7-trihydroxy groups.

Supplementary Materials: Supplementary materials are available online, include: 1 . The visible spectra of (4)_(15). 2. The UV spectra of low-concentration chrysin and chrysin-Fe ${ }^{2+}$ complex. 3. Preferential conformation-based ball-and-stick model of baicalein- $\mathrm{Fe}^{2+}$ complex. 4 . Information about origin of baicalein and chrysin.

Acknowledgments: This work was supported by the National Nature Science Foundation of China (81573558) and Guangdong Science and Technology Project (2017A050506043, 2017A030312009).

Author Contributions: Xican Li and Dongfeng Chen conceived and designed the experiments; Xiaozhen Wang and Hong Xie performed the chemical and antioxidant experiments; Yage Tian performed the MTT assay; Yulu Xie performed the deoxyribose degradation assay; Xican Li wrote the paper. Chuanbing Chen and Yage Tian revised the paper. All authors read and approved the final manuscript.

Conflicts of Interest: The authors confirm that there are no conflicts of interest.

\section{Abbreviations}

$\begin{array}{ll}\text { ABTS } & 2,2^{\prime} \text {-azino-bis (3-ethylbenzo-thiazoline-6-sulfonic acid) } \\ \text { bmMSCs } & \text { bone marrow-derived mesenchymal stem cells } \\ \text { DMEM } & \text { Dulbecco's modified Eagle's medium } \\ \text { ET } & \text { Electron transfer } \\ \text { FBS } & \text { Fetal bovine serum } \\ \text { FRAP } & \text { ferric ion reducing antioxidant power } \\ \text { MTT } & \text { methyl thiazolyl tetrazolium } \\ \text { Neocuproine } & \text { 2,9-dimethyl-1,10-phenanthroline } \\ \text { PTIO• } & \text { 2-phenyl-4,4,5,5-tetramethylimidazoline-1-oxyl-3-oxide radical } \\ \text { ROS } & \text { reactive oxygen species } \\ \text { Trolox } & ( \pm) \text {-6-hydroxyl-2,5,7,8-tetramethlychromane-2-carboxylic acid } \\ \text { TPTZ } & \text { 2,4,6-tripyridyl triazine }\end{array}$

\section{References}

1. Waite, G.N.; Waite, L.R.; Hughes, E.F.; Balcavage, W.X. Biophotonic hydrogen peroxide production by antibodies, T cells, and T-cell membranes. Biochem. Biophys. Res. Commun. 2005, 338, 1110-1117. [CrossRef] [PubMed] 
2. Lloyd, D.R.; Phillips, D.H. Oxidative DNA damage mediated by copper(II), iron(II) and nickel(II) fenton reactions: Evidence for site-specific mechanisms in the formation of double-strand breaks, 8-hydroxydeoxyguanosine and putative intrastrand cross-links. Mutat. Res. 1999, 424, 23-36. [CrossRef]

3. Li, X.; Gao, Y.; Li, F.; Liang, A.; Xu, Z.; Bai, Y.; Mai, W.; Han, L.; Chen, D. Maclurin protects against hydroxyl radical-induced damages to mesenchymal stem cells: Antioxidant evaluation and mechanistic insight. Chem. Biol. Interact. 2014, 219, 221-228. [CrossRef] [PubMed]

4. Li, X.; Wei, G.; Wang, X.; Liu, D.H.; Deng, R.D.; Li, H.; Zhou, J.H.; Li, Y.W.; Zeng, H.P.; Chen, D.F. Targeting of the Shh pathway by atractylenolides promotes chondrogenic differentiation of mesenchymal stem cells. Biol. Pharm. Bull. 2012, 35, 1328-1335. [CrossRef] [PubMed]

5. Denu, R.A.; Hematti, P. Effects of Oxidative Stress on Mesenchymal Stem Cell Biology. Oxid. Med. Cell. Longev. 2016, 2016, 2989076. [CrossRef] [PubMed]

6. Shi, Y.; Hu, Y.; Lv, C.; Tu, G. Effects of Reactive Oxygen Species on Differentiation of Bone Marrow Mesenchymal Stem Cells. Ann. Transpl. 2016, 21, 695-700. [CrossRef]

7. Tsay, J.; Yang, Z.; Ross, F.P.; Cunningham-Rundles, S.; Lin, H.; Coleman, R.; Mayer-Kuckuk, P.; Doty, S.B.; Grady, R.W.; Giardina, P.J.; et al. Bone loss caused by iron overload in a murine model: Importance of oxidative stress. Blood 2010, 116, 2582-2589. [CrossRef] [PubMed]

8. Datta, I.; Bhonde, R. Can mesenchymal stem cells reduce vulnerability of dopaminergic neurons in the substantia nigra to oxidative insult in individuals at risk to Parkinson's disease? Cell Biol. Int. 2012, 36, 617-624. [CrossRef] [PubMed]

9. Li, X.; Han, L.; Li, Y.; Zhang, J.; Chen, J.; Lu, W.; Zhao, X.; Lai, Y.; Chen, D.; Wei, G. Protective effect of sinapine against hydroxyl radical-induced damage to mesenchymal stem cells and possible mechanisms. Chem. Pharm. Bull. 2016, 64, 319-325. [CrossRef] [PubMed]

10. Wang, C.; Meng, H.; Wang, X.; Zhao, C.; Peng, J.; Wang, Y. Differentiation of Bone Marrow Mesenchymal Stem Cells in Osteoblasts and Adipocytes and its Role in Treatment of Osteoporosis. Med. Sci. Monit. 2016, 22, 226-233. [CrossRef] [PubMed]

11. Li, X.; Chen, D.; Mai, Y.; Wen, B.; Wang, X. Concordance between antioxidant activities in vitro and chemical components of Radix Astragali (Huangqi). Nat. Prod. Res. 2012, 26, 1050-1053. [CrossRef] [PubMed]

12. Wang, G.; Li, X.; Zeng, H. Synthesis, antioxidation activity of (E)-9-p-Tolyl-3-[2-(8-hydroxy-quinol-2-yl)vinyl]-carbazole and (E)-9-(p-Anisyl)-3-[2-(8-hydroxy-quinol-2-yl) vinyl]-carbazole and their induction proliferation of mesenchymal stem cells. Acta Chim. Sin. 2009, 67, 974-982.

13. Wang, T.; Zeng, G.; Li, X.; Zeng, H. In vitro studies on the antioxidant and protective effect of 2-substituted-8-hydroxyquinoline derivatives against $\mathrm{H}_{2} \mathrm{O}_{2}$-induced oxidative stress in BMSCs. Chem. Biol. Drug Des. 2010, 75, 214-222. [CrossRef] [PubMed]

14. Chen, F.; Liu, Y.; Wong, N.K.; Xiao, J.; So, K.F. Oxidative Stress in Stem Cell Aging. Cell Transpl. 2017, 26, 1483-1495. [CrossRef] [PubMed]

15. Nakao, Y.; Yoshihara, H.; Fujimori, K. Suppression of Very Early Stage Of Adipogenesis by Baicalein, a Plant-Derived Flavonoid through Reduced Akt-C/EBP alpha-GLUT4 Signaling-Mediated Glucose Uptake in 3T3-L1 Adipocytes. PLoS ONE 2016, 11, e0163640. [CrossRef] [PubMed]

16. Seo, M.J.; Choi, H.S.; Jeon, H.J.; Woo, M.S.; Lee, B.Y. Baicalein inhibits lipid accumulation by regulating early adipogenesis and m-TOR signaling. Food Chem. Toxicol. 2014, 67, 57-64. [CrossRef] [PubMed]

17. Li, S.F.; Tang, J.J.; Chen, J.; Zhang, P.; Wang, T.; Chen, T.Y.; Yan, B.; Huang, B.; Wang, L.; Huang, M.J.; et al. Regulation of bone formation by baicalein via the mTORC1 pathway. Drug Des. Dev. Ther. 2015, 9, 5169-5183.

18. Gao, Z.; Huang, K.; Xu, H. Protective effects of flavonoids in the roots of Scutellaria baicalensis Georgi against hydrogen peroxide-induced oxidative stress in HS-SY5Y cells. Pharmacol. Res. 2001, 43, 173-178. [CrossRef] [PubMed]

19. Yu, X.; He, G.; Du, G. Neuroprotective effect of baicalein in patients with Parkinson's disease. Zhongguo Zhong Yao Za Zhi 2012, 37, 421-425. [PubMed]

20. Yoshino, M.; Murakami, K. Interaction of iron with polyphenolic compounds: Application to antioxidant characterization. Anal. Biochem. 1998, 257, 40-44. [CrossRef] [PubMed]

21. Shieh, D.E.; Liu, L.T.; Lin, C.C. Antioxidant and free radical scavenging effects of baicalein, baicalin and wogonin. Anticancer Res. 2000, 20, 2861-2865. [PubMed] 
22. Ren, J.; Meng, S.; Lekka, C.E.; Kaxiras, E. Complexation of flavonoids with iron: Structure and optical signatures. J. Phys. Chem. B 2008, 112, 1845-1850. [CrossRef] [PubMed]

23. Perez, C.A.; Wei, Y.; Guo, M. Iron-binding and anti-Fenton properties of baicalein and baicalin. J. Inorg. Biochem. 2009, 103, 326-332. [CrossRef] [PubMed]

24. Piao, X.L.; Cho, E.J.; Jang, M.H. Cytoprotective effect of baicalein against peroxynitrite-induced toxicity in LLC-PK(1) cells. Food Chem. Toxicol. 2008, 46, 1576-1581. [CrossRef] [PubMed]

25. Li, X.; Mai, W.; Wang, L.; Han, W. A hydroxyl-scavenging assay based on DNA damage in vitro. Anal. Biochem. 2013, 438, 29-31. [CrossRef] [PubMed]

26. Li, X.; Hu, Q.; Jiang, S.; Li, F.; Lin, J.; Han, L.; Hong, Y.; Lu, W.; Gao, Y.; Chen, D. Flos Chrysanthemi Indici protects against hydroxyl-induced damages to DNA and MSCs via antioxidant mechanism. J. Saudi Chem. Soc. 2015, 19, 454-460. [CrossRef]

27. Li, X.C.; Liu, J.J.; Lin, J.; Wang, T.T.; Huang, J.Y.; Lin, Y.Q.; Chen, D.F. Protective effects of dihydromyricetin against $\bullet \mathrm{OH}$-Induced mesenchymal stem cells damage and mechanistic chemistry. Molecules 2016, 21, 604. [CrossRef] [PubMed]

28. Lin, J.; Li, X.; Chen, L.; Lu, W.; Chen, X.; Han, L.; Chen, D. Protective effect against hydroxyl radical-induced DNA damage and antioxidant mechanism of [6]-gingerol: A Chemical Study. Bull. Korean Chem. Soc. 2014, 35, 1633-1638. [CrossRef]

29. Fang, Y.Z.; Zheng, R.L. Reactive oxygen species in theory and application of free radical biology. In Theory and Application of Free Radical Biology, 2nd ed.; Science Press: Beijing, China, 2002; pp. 98-99.

30. Goldstein, S.; Russo, A.; Samuni, A. Reactions of PTIO and carboxy-PTIO with $\bullet \mathrm{NO}, \bullet \mathrm{NO}_{2}$, and $\bullet \mathrm{O}_{2}{ }^{-}$. J. Biol. Chem. 2003, 278, 50949-50955. [CrossRef] [PubMed]

31. Gulcin, I. Antioxidant activity of food constituents: An overview. Arch. Toxicol. 2012, 86, 345-391. [CrossRef] [PubMed]

32. Marino, T.; Galano, A.; Russo, N. Radical scavenging ability of gallic acid toward $\mathrm{OH}$ and OOH radicals. Reaction mechanism and rate constants from the density functional theory. J. Phys. Chem. B 2014, 118, 10380-10389. [CrossRef] [PubMed]

33. Li, X.; Lin, J.; Gao, Y.; Tian, R.; Chen, D. Nitric Oxide (NO) as Antioxidant Protects HT22 Cells and Biomolecules against Fenton's Reagent-Induced Damages via Multiple Pathways. Chemistryselect 2016, 1, 585-589. [CrossRef]

34. Macakova, K.; Mladenka, P.; Filipsky, T.; Riha, M.; Jahodar, L.; Trejtnar, F.; Bovicelli, P.; Proietti Silvestri, I.; Hrdina, R.; Saso, L. Iron reduction potentiates hydroxyl radical formation only in flavonols. Food Chem. 2012, 135, 2584-2592. [CrossRef] [PubMed]

35. Huang, Y.K.; Chang, T.C.; Sheu, J.R.; Wen, K.H.; Chou, D.S. Comparison of free radical formation induced by baicalein and pentamethyl-hydroxychromane in human promyelocytic leukemia cells using electron spin resonance. J. Food Drug Anal. 2014, 22, 379-390. [CrossRef] [PubMed]

36. Laughton, M.J.; Halliwell, B.; Evans, P.J.; Hoult, J.R. Antioxidant and pro-oxidant actions of the plant phenolics quercetin, gossypol and myricetin. Effects on lipid peroxidation, hydroxyl radical generation and bleomycin-dependent damage to DNA. Biochem. Pharmacol. 1989, 38, 2859-2865. [CrossRef]

37. Mladěnka, P.; Macáková, K.; Filipský, T.; Zatloukalová, L.; Jahodář, L.; Bovicelli, P.; Silvestri, I.P.; Hrdina, R.; Saso, L. In vitro analysis of iron binding activity of flavonoids. J. Inorg. Biochem. 2011, 105, 693-701. [CrossRef] [PubMed]

38. Vlachodimitropoulou, E.; Sharp, P.A.; Naftalin, R.J. Quercetin-iron chelates are transported via glucose transporters. Free Radic. Biol. Med. 2011, 50, 934-944. [CrossRef] [PubMed]

39. Riha, M.; Karlickova, J.; Filipsky, T.; Macakova, K.; Rocha, L.; Bovicelli, P.; Silvestri, I.P.; Saso, L.; Jahodar, L.; Hrdina, R.; et al. In vitro evaluation of copper-chelating properties of flavonoids. RSC Adv. 2014, 4, 32628-32638. [CrossRef]

40. Mira, L.; Fernandez, M.T.; Santos, M.; Rocha, R.; Florencio, M.H.; Jennings, K.R. Interactions of flavonoids with iron and copper ions: A mechanism for their antioxidant activity. Free Radic. Res. 2002, 36, 1199-1208. [CrossRef] [PubMed]

41. Ravichandran, R.; Rajendran, M.; Devapiriam, D. Antioxidant study of quercetin and their metal complex and determination of stability constant by spectrophotometry method. Food Chem. 2014, 146, 472-478. [CrossRef] [PubMed] 
42. Ikeda, N.E.; Novak, E.M.; Maria, D.A.; Velosa, A.S.; Pereira, R.M. Synthesis, characterization and biological evaluation of Rutin-zinc(II) flavonoid -metal complex. Chem. Biol. Interact. 2015, 239, 184-191. [CrossRef] [PubMed]

43. Xiao, C.H. Chemistry of Chinese Materia Medica, 3rd ed.; Shanghai Scientific \& Technical Publishers: Shanghai, China, 1997; pp. 289-299.

44. Schär, M.Y.; Curtis, P.J.; Hazim, S.; Ostertag, L.M.; Kay, C.D.; Potter, J.F.; Cassidy, A. Orange juice-derived flavanone and phenolic metabolites do not acutely affect cardiovascular risk biomarkers: A randomized, placebo-controlled, crossover trial in men at moderate risk of cardiovascular disease. Am. J. Clin. Nutr. 2015, 101, 931-938. [CrossRef] [PubMed]

45. Van der Velpen, V.; Hollman, P.C.; van Nielen, M.; Schouten, E.G.; Mensink, M.; van't Veer, P.; Geelen, A. Large inter-individual variation in isoflavone plasma concentration limits use of isoflavone intake data for risk assessment. Eur. J. Clin. Nutr. 2014, 68, 1141-1147. [CrossRef] [PubMed]

46. Chen, P.P.; Zhang, J.M.; Wang, Q. Analysis of iron and copper contents in plasma and hair for patients with coronary heart disease. Med. Sci. 2003, 38, 89-90.

47. Chen, D.F.; Li, X.C.; Xu, Z.W.; Liu, X.B.; Du, S.H.; Li, H.; Zhou, J.H.; Zeng, H.P.; Hua, Z.C. Hexadecanoic Acid from Buzhong Yiqi Decoction Induced Proliferation of Bone Marrow Mesenchymal Stem Cells. J. Med. Food 2010, 13, 967-975. [CrossRef] [PubMed]

48. Li, X. Solvent effects and improvements in the deoxyribose degradation assay for hydroxyl radical-scavenging. Food Chem. 2013, 141, 2083-2088. [CrossRef] [PubMed]

49. Li, X. 2-Phenyl-4,4,5,5-tetramethylimidazoline-1-oxyl 3-Oxide (PTIO-) Radical Scavenging: A New and Simple Antioxidant Assay In Vitro. J. Agric. Food Chem. 2017, 65, 6288-6297. [CrossRef] [PubMed]

50. Li, X.; Han, W.; Mai, W.; Wang, L. Antioxidant activity and mechanism of Tetrahydroamentoflavone in vitro. Nat. Prod. Commun. 2013, 8, 787-789.

51. Benzie, I.F.F.; Strain, J.J. The ferric reducing ability of plasma (FRAP) as a measure of "antioxidant power": The FRAP assay. Anal. Biochem. 1996, 239, 70-76. [CrossRef] [PubMed]

52. Li, X.; Jiang, Q.; Wang, T.; Liu, J.; Chen, D. Comparison of the Antioxidant Effects of Quercitrin and Isoquercitrin: Understanding the Role of the 6"-OH Group. Molecules 2016, 21, 1246. [CrossRef] [PubMed]

53. Li, X.; Mai, W.; Chen, D. Chemical study on protective effect against hydroxyl-induced DNA damage and antioxidant mechanism of myricitrin. J. Chin. Chem. Soc. 2014, 61, 383-391. [CrossRef]

Sample Availability: Sample of the compound baicalein is available from the authors.

(C) 2018 by the authors. Licensee MDPI, Basel, Switzerland. This article is an open access article distributed under the terms and conditions of the Creative Commons Attribution (CC BY) license (http:/ / creativecommons.org/licenses/by/4.0/). 